\title{
The Effect of Feed Supplementation with Fermented Red Seaweed (Kappaphycus alvarezii) on Growth and Survival of Whiteleg Shrimp (Litopenaeus vannamei) Post-Larvae Culture
}

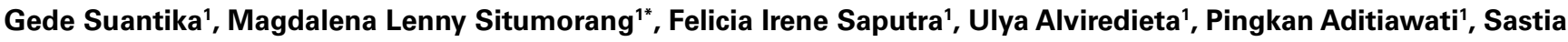 \\ Prama Putri', \\ ${ }^{1}$ Microbial Biotechnology Research Group, School of Life Sciences and Technology, Institut Teknologi Bandung, Bandung, Indonesia \\ ${ }^{2}$ Department of Advanced Science and Biotechnology, Osaka University, Osaka, Japan
}

ARTICLE INFO

Article history:

Received October 28, 2020

Received in revised form July 30, 2021

Accepted August 15, 2021

KEYWORDS:

Shrimp,

Litopenaeus vannamei,

fermented,

red seaweed,

Kappaphycus alvarezii,

growth,

survival

\begin{abstract}
This study was aimed to investigate the effect of novel shrimp diet supplemention with fermented red seaweed Kappaphycus alvarezii on growth and survival of whiteleg shrimp (Litopenaeus vannamei) post-larvae culture. The research consisted of three consecutive steps: (1) preliminary study on Kappaphycus alvarezii fermentation, (2) feed formulation and proximate analysis, (3) performance test of commercial feed (C), commercial $+0.5 \% \mathrm{~K}$. alvarezii (EF1), and commercial $+1.5 \%$ fermented $K$. alvarezii (EF2). Following 15 days of feeding, the highest biomass, specific growth rate and survival were achieved in EF2 treatment $(\mathbf{1 . 6 0} \pm \mathbf{0 . 2 1} \mathrm{g}, \mathbf{1 0 . 8 8} \pm \mathbf{0 . 8 6} \% / \mathrm{d}, \mathbf{9 1 . 6 7 \pm 1 . 5 3 \% )}$, significantly different from control $(0.99 \pm 0.09 \mathrm{~g}, 7.72 \pm 0.63 \% / \mathrm{d}, 47.00 \pm 5.00 \%)(\mathrm{p}<0.05)$. Overall, this study suggested that the dietary supplementation of $1.5 \%$ fermented $K$. alvarezii can enhance the growth and survival of whiteleg shrimp during the nursery phase.
\end{abstract}

\section{Introduction}

Shrimp production worldwide is expected to grow by more than $5.6 \%$ annually. In 2017 , the global market for shrimp, including farm-raised (aquaculture) and wild-caught shrimp, was valued at around $\$ 40$ billion (FAO 2020). The dominant species of farmed shrimp, Litopenaeus vannamei, or whiteleg shrimp, accounts for about $\$ 14$ billion alone. The Indonesian aquaculture shrimp industry is currently in a strong competitive position in the global market, with an expected growth of $8 \%$ per year through 2022 , surpassing global growth rates of 5.6\% (Rubel et al. 2019).

Unfortunately, white shrimps are vulnerable to environmental stress and Vibrio harveyi as pathogen during hatchery or nursery phase. Vibriosis disease leads shrimps into massive mortality and disserves aquaculture industrial economy (Liu et al. 2004) Several strategies such as application of recirculating aquaculture system (RAS) technology (Suantika et al. 2003), zero water discharge (ZWD) (Suantika et al.

\footnotetext{
* Corresponding Author

E-mail Address: situmorangml@sith.itb.ac.id
}

2015), hybrid ZWD-RAS (Suantika et al. 2018), as well as probiotic, prebiotic and/or synbiotic administration through shrimp feed (Suantika et al. 2013; Situmorang et al. 2020, 2021; Uawisetwathana et al. 2021) have been developed to prevent Vibrio dominancy and distribution on shrimp culture by controlling the water quality and microbial community itself. Along with system improvement, resistance against vibriosis syndrome could be increased through the manipulation of shrimp feed. Several studies are focused on the use of seaweed products and byproducts as immunostimulant agent in shrimps (Chojnacka et al. 2012; Sivagnanavelmurugan et al. 2014). Even though the use of seaweed is proven in enhancing shrimp resistance against vibriosis due to its polysaccharide properties (Chojnacka et al. 2012; Marudhupandi and Inbakandan 2015), in many cases the effect of seaweed application and supplementations contribute in lowering the growth and uncertainty of immune response. Based on this situation, an effort to enrich the nutritional properties of seaweed responsible for immunity improvement such as the availability of essential amino acids and fatty acids should be taken as a serious consideration. Onealternativestrategytoovercomethisconsideration 
is nutrition improvement of seaweed products by fermentation (Han et al. 2012). Several microbial fermentation agents which has been known due to its ability improving the amino acid profile of plantbased raw material, including Lactobacillus brevis, L. casei (Uchida and Miyoshi 2013), L. plantarum, L. acidophilus (Uchida and Miyoshi 2013; Swain et al. 2014), Leuconostoc mesenteroides, Pediococcus pentosaceus, Weisella confuse, Tetragenococcus halophilus (Uchida and Miyoshi 2013; Nuraida 2015), and Saccharomyces cerevisiae which has ability to enhance amino acid profile of red seaweed Kappaphycus alvarezii (Ferreira et al. 2010).

This research was aimed to evaluate the effect of shrimp feed supplementation with fermented $K$. alvarezii at the concentration of $0.5 \%$ and $1.5 \%$ compared to the commercial feed as control treatment on the growth and survival of white shrimp postlarvae culture.

\section{Materials and Methods}

\subsection{Preparation and Fermentation of Kappaphycus alvarezii}

\subsubsection{Source of $K$. alvarezii}

The raw K. alvarezii were obtained from seaweed farm in Bali and provided by PT. Gapura Akua Kultiva, Bandung, Indonesia.

\subsubsection{Rinsing and Milling of $K$. alvarezii}

$K$. alvarezii were washed three times with freshwater to remove debris and salt residues, chopped $( \pm 5 \mathrm{~cm})$, and dried at $60-75^{\circ} \mathrm{C}$ for $24-48 \mathrm{~h}$. Dried K. alvarezii were further milled using $250 \mu \mathrm{m}$ disc mill to obtain powder.

\subsubsection{Fermentation of $K$. alvarezii}

Fermentation of $K$. alvarezii was done using $S$. cerevisiae at $25^{\circ} \mathrm{C}, 125 \mathrm{rpm}$. Fermentation medium was prepared using $20 \mathrm{~g} \mathrm{~K}$. alvarezii powder, $1.5 \mathrm{~g}$ corn starch powder, $0.4 \mathrm{~g}$ urea, $1 \mathrm{~g}$ glucose, solved in $200 \mathrm{ml}$ aquadest. The activation and adaptation of $S$. cerevisiae was done to build the capacity of $S$. cerevisiae to use K. alvarezii substrate (Asaduzzaman 2007), following the consecutive steps: (1) activation of $S$. cerevisiae in $100 \%$ premix medium (potato dextrose broth or PDB), (2) adaptation of S. cerevisiae in $25 \% \mathrm{~K}$. alvarezii medium and $75 \%$ premix medium, (3) adaptation of $S$. cerevisiae in $50 \% \mathrm{~K}$. alvarezii medium and 50\% premix medium, (4) adaptation of $S$. cerevisiae in $75 \% \mathrm{~K}$. alvarezii medium and $25 \%$ premix medium, and (5) activation of $S$. cerevisiae in $100 \%$ K. alvarezii medium. Following the activation and adaptation of $S$. cerevisiae in $K$. alvarezii medium, the K. alvarezii medium was fermented for $72 \mathrm{~h}$ by $10 \%$ active-S. cerevisiae. The cell density of S. cerevisiae in $100 \% \mathrm{~K}$. alvarezii medium was measured using haemocyte count, while $\mathrm{pH}$ value was measured every six hour to plot the growth curve (Asaduzzaman 2007). The fermentation was stopped after $72 \mathrm{~h}$ and the fermented $K$. alvarezii medium was oven dried at $60-75^{\circ} \mathrm{C}$ for $24-48 \mathrm{~h}$ and further milled using $250 \mu \mathrm{m}$ disc mill to obtain fermented $K$. alvarezii powder.

\subsection{Proximate Analysis of Raw and Fermented K. alvarezii}

Proximate analyzes were done on five hundred gram of each raw and fermented $K$. alvarezii (RM1 and RM2 respectively) at PT. Saraswanti Indo Genetech, Bogor, Indonesia, to measure the total energy, energy from fat, dry matter, water content, ash content, total lipid, total protein, total carbohydrate and fiber, amino acid profile and fatty acid profile (AOAC 1999).

\subsection{Experimental Feeding \\ 2.3.1. System Set Up}

The sea water in tank was sterilized using 60 ppm chlorine and aerated for $24 \mathrm{~h}$. After $24 \mathrm{~h}$, water was neutralized by Na-thiosulphate (1:1). Following sterilization, the three days-acclimated $L$. vannamei (PL-13) were transferred to 701 hatchery tanks containing sea water at $30 \mathrm{ppt}, 28^{\circ} \mathrm{C}, \mathrm{pH} 8$, and DO $8.0 \mathrm{mg} / \mathrm{l}$, at the stocking density of three individuals per liter (APHA 1999).

\subsubsection{Feeding Regime}

Three types of feed were tested in this study: (1) commercial feed as control (C), (2) commercial feed supplemented with $0.5 \% \mathrm{~K}$. alvarezii (EF1), and (3) commercial feed supplemented with $1.5 \%$ fermented K. alvarezii (EF2). Daily feeding was done in three portions (8 AM, $1 \mathrm{PM}$ and $8 \mathrm{PM}$ ) at the rate of $10 \%$ body weight during 15 days experiment (T0-T14). The following illustration shows the experimental layout during the feed trial. Each type of feed was tested in three replicates (triplo), which showed by the different numbers. 


\subsubsection{Water Quality Measurement}

The value of water quality physical-chemical parameters were controlled within the tolerance range and examined per two days during 15 days feed performance test. The water removal daily is $2.5-5.0 \%$ per day to maintain the salinity in case of evaporation. The maintenance of physicalchemical parameters were required to reduce the experimental variables and truly focus on effect of fermented $K$. alvarezii treatment. The dissolved oxygen and water temperature were consecutively maintained approximately at $8.0 \mathrm{mg} / \mathrm{l}, 28^{\circ} \mathrm{C}$ and measured utilizing Hach®40qd with $0.005 \mathrm{mg} / \mathrm{l}$ and $0.05^{\circ} \mathrm{C}$. pH value was maintained at 8.0 measured with Mettler-Toledo®, 0.005 accuracy. Water salinity was measured using ATAGO ${ }^{\circledR}$ refractometer, $0.5 \mathrm{ppt}$ and maintained at $30 \mathrm{ppt}$. Ammonium, nitrite and nitrate concentration were measured with Sera ${ }^{\circledR}$ kit and maintained within the tolerance range (Wyban et al. 1995; Abowei 2010).

\subsubsection{Biological Analyses}

Twenty shrimp were sampled randomly from each replicate tank at the initial (T0), middle (T7) and final (T14) period of feeding test for biological analyses. Shrimp length was measured using scientific ruler. Shrimp weight was measured on analytical scale to calculate specific growth rate (SG), mean body weight (MBW) and biomass value. Besides growth performance value, survival of shrimp PL was calculated as important aim of this research. The equation to calculate the growth performance parameter and survival were shown below (Suantika et al. 2012):

$$
\begin{gathered}
S G=\frac{\left(\ln W_{t}-\ln W_{0}\right)}{t} \times 100 \% \\
M B W=\frac{\text { Wshrimp }}{n}
\end{gathered}
$$

Biomass $=$ Shrimp population $\times$ MBW

$$
\text { Survival }=\frac{N_{t}}{N_{o}} \times 100 \%
$$

Where:

$\mathrm{W}_{\mathrm{t}} \quad$ = final weight of $L$. vannamei PL

$\mathrm{W}_{0}^{\mathrm{t}} \quad=$ initial weight of $L$. vannamei PL

$\mathrm{t}=$ duration of experiment

$\mathrm{n} \quad=$ amount of $L$. vannamei weighed

$\mathrm{N}_{\mathrm{t}} \quad$ = amount of shrimp on T14

No = amount of shrimp on T0
The food conversion ratio (FCR) and feed efficiency ratio (FER) were calculated using the following formula (Wyban et al. 1995):

$$
\begin{aligned}
& \text { FCR }=\frac{\text { Amount of feed }}{\left(W_{t}-W_{0}\right)} \\
& \text { FER }=\frac{\left(W_{t}-W_{0}\right)}{\text { Amount of feed }}
\end{aligned}
$$

Where:

$\mathrm{W}_{\mathrm{t}} \quad$ = final weight of $L$. vannamei $\mathrm{PL}$

$\mathrm{W}_{0} \quad=$ initial weight of $L$. vannamei PL

\subsubsection{Statistical Analysis}

Survival data were first normalized using an arcsine transformation before statistical analysis (Situmorang et al. 2021). To evaluate the differences between treatment groups, data on growth and survival parameters were analyzed using one-way ANOVA and followed by Duncan posthoc Test with 95\% confidence intervals. All statistical analyses were performed using SPSS ${ }^{\circledR}$ Version 24.0.

\section{Results}

\subsection{Proximate Analysis}

The result of proximate analysis on K. alvarezii as feed ingredient is shown in Table 1 . It was found that the total protein in fermented K. alvarezii (RM2) was three times higher compared to raw K. alvarezii (RM1) itself. The amino acid (Table 2) and fatty acid (Table 3) content in RM2 were also found to be higher than RM1, except for tryptophane (zero value) in both RMs. Table 2 shows the escalation of the amino acid contents of the fermented $K$. alvarezii (RM2) and the feed with RM2 supplementation compared to other experimental feeds.

According to the feed proximate result, the general proximate (Table 1 ) and fatty acid profile (Table 3 ) for commercial feed supplemented with $0.5 \% \mathrm{~K}$. alvarezii (EF1) and commercial feed supplemented with $1.5 \%$ fermented K. alvarezii (EF2) have had similar value, relatively similar to the nutritional value of the commercial feed (C).

\subsection{Shrimp Growth and Survival Performance}

The feeding performance test was performed to verify the effect of feed supplementation with fermented K. alvarezii on the growth and survival of shrimp postlarvae. During the test, physical and chemical water quality parameters were maintained at the tolerance level for shrimp PL (Table 4). 
Table 1. Proximate of $K$. alvarezii as feed ingredients and different experimental feeds

\begin{tabular}{|c|c|c|c|c|c|c|}
\hline \multirow{3}{*}{ Proximate component } & \multirow{3}{*}{ Unit } & \multicolumn{5}{|c|}{ Nutrition value } \\
\hline & & \multicolumn{2}{|c|}{ Proximate component } & \multicolumn{3}{|c|}{ As feed } \\
\hline & & RM1 & RM2 & $\mathrm{C}$ & EF1 & EF2 \\
\hline Total energy & & 288.38 & 308.81 & 2926.7 & 2913.4 & 2887.3 \\
\hline Energy from fat & $\mathrm{kcal} / 100 \mathrm{~g}$ & 1.98 & 2.61 & 37.2 & 37.0 & 36.7 \\
\hline Dry matter & & 91.04 & 97.33 & 79.0 & 88.9 & 89.0 \\
\hline Water content & & 8.96 & 2.67 & 9.9 & 0 & 0 \\
\hline Ash content & $\%$ & 19.22 & 20.49 & 11.0 & 11.0 & 11.1 \\
\hline Total lipid & & 0.22 & 0.29 & 4.1 & 4.1 & 4.1 \\
\hline Total protein & & 3.26 & 9.13 & 27.5 & 27.4 & 27.2 \\
\hline Total carbohydrate & & 68.34 & 67.42 & 36.4 & 36.5 & 36.8 \\
\hline Fiber & & 4.6 & 6.78 & 0 & 0 & 0.1 \\
\hline
\end{tabular}

Table 2. Amino acid profile of raw materials of feed and feed variants

\begin{tabular}{|c|c|c|c|c|c|c|c|}
\hline \multirow{3}{*}{ Amino acid } & \multirow{3}{*}{ Unit } & \multicolumn{6}{|c|}{ Nutrition value } \\
\hline & & \multicolumn{2}{|c|}{ As raw materials } & \multicolumn{4}{|c|}{ As feed } \\
\hline & & RM1 & RM2 & C & EF1 & EF2 & $\begin{array}{c}\text { Reference } \\
\text { (Velasco et al. 2000) }\end{array}$ \\
\hline L-Histidine* & $\mathrm{g} / \mathrm{kg}$ & 0.213 & 0.362 & 7.573 & 8.510 & 12.742 & 4.00 \\
\hline L-Threonine* & & 1.532 & 1.826 & 13.947 & 20.851 & 40.403 & 7.30 \\
\hline L-Valine* & & 1.557 & 2.000 & 13.654 & 20.672 & 42.647 & 8.60 \\
\hline L-Isoleusine* & & 1.189 & 1.461 & 6.142 & 8.403 & 13.944 & 8.20 \\
\hline L-Leusine* & & 2.196 & 2.657 & 12.062 & 17.416 & 33.211 & 13.80 \\
\hline L-Phenylalanine* & & 1.305 & 1.607 & 23.094 & 32.974 & 61.535 & 8.60 \\
\hline L-Arginine* & & 1.511 & 1.580 & 16.916 & 22.770 & 40.116 & 13.00 \\
\hline L-Glycine & & 1.566 & 2.011 & 20.125 & 26.464 & 38.552 & 8.30 \\
\hline L-Alanine & & 1.839 & 2.433 & 0 & 6.879 & 23.062 & 8.20 \\
\hline L-Aspartic Acid & & 2.941 & 3.779 & 0 & 7.129 & 29.358 & 21.50 \\
\hline L-Glutamic Acid & & 3.512 & 5.091 & 0 & 8.369 & 35.519 & 26.70 \\
\hline L-Proline & & 1.285 & 1.602 & 0 & 13.390 & 55.177 & 9.40 \\
\hline L-Serine & & 1.487 & 1.768 & 0 & 15.986 & 74.333 & 9.00 \\
\hline L-Tyrosine & & 0.693 & 0.684 & 0 & 5.848 & 23.396 & 4.00 \\
\hline L-Lysine* & & 1.415 & 1.283 & 0 & 6.768 & 25.810 & 12.30 \\
\hline L-Methionine* & & 0.503 & 0.541 & 0 & 3.154 & 9.986 & 5.40 \\
\hline L-Trytophan & & 0 & & 1.662 & 1.654 & 1.637 & 3.16 \\
\hline
\end{tabular}

$\mathrm{RM} 1=K$. alvarezii, $\mathrm{RM} 2=$ fermented $K$. alvarezii, $\mathrm{C}=$ commercial feed, $\mathrm{EF} 1=$ commercial feed $+0.5 \%$. alvarezii, $\mathrm{EF} 2=$ commercial feed $+1.5 \%$ K. alvarezii; *essential amino acids

\section{Discussion}

\subsection{Proximate Analysis of $K$. alvarezii as Feed Ingredients}

Based on the result of proximate analysis on $K$. alvarezii as feed ingredients (Table 1), it is known that total protein in fermented K. alvarezii (RM2) was increased three times compared to raw $K$. alvarezii (RM1) itself. This is potentially due to the character of $S$. cerevisiae as fermentation bio-agent, which is high in protein of up to $40 \%$ dry matter (Yamada and Sgarbieri 2005). The purpose of raw materials supplementation in shrimp commercial feed are: (1) to fulfill the nutrition value of shrimp diet, (2) to add essential nutrients for shrimp growth such as amino acid and fatty acid of the diet, and (3) to maximize the cost-effectiveness of diet production. As mentioned earlier, $S$. cerevisiae may enhance the amino acid contents in feed (Yamada and Sgarbieri 2005). Table 2 shows the escalation of the amino acid contents of the fermented K. alvarezii (RM2) and the feed with RM2 supplementation compared to other 
Table 3. Fatty acid profile of raw materials of feed and feed variants

\begin{tabular}{|c|c|c|c|c|c|c|c|}
\hline \multirow{2}{*}{\multicolumn{2}{|c|}{ Fatty acid }} & \multirow{3}{*}{ Unit } & \multicolumn{5}{|c|}{ Nutrition value } \\
\hline & & & \multicolumn{2}{|c|}{ As raw materials } & \multicolumn{3}{|c|}{ As feed } \\
\hline & & & RM1 & RM2 & $\mathrm{C}$ & EF1 & EF2 \\
\hline Myristoleic acid & C 14:0 & $\%$ & 0.213 & 0.362 & 2.498 & 2.485 & 2.460 \\
\hline Palmitate acid & C 16:0 & & 1.532 & 1.826 & 8.889 & 8.845 & 8.758 \\
\hline Palmitoleic acid & C $16: 1$ & & 1.557 & 2.000 & 2.542 & 2.530 & 2.504 \\
\hline Stearic acid & C $18: 0$ & & 1.189 & 1.461 & 2.213 & 2.202 & 2.180 \\
\hline Oleic acid & C $18: 1 \omega 9 C$ & & 2.196 & 2.657 & 6.311 & 6.280 & 6.217 \\
\hline Linoleic acid & C $18: 2 \omega 6 C$ & & 1.305 & 1.607 & 8.613 & 8.570 & 8.485 \\
\hline Linolenic acid $\omega 3$ & C $18: 3 \omega 3$ & & 1.511 & 1.580 & 0.978 & 0.973 & 0.963 \\
\hline Arachidonic acid & С $20: 4 \omega 6$ & & 1.566 & 2.011 & 0.551 & 0.548 & 0.543 \\
\hline Omega-6 & & & 1.839 & 2.433 & 9.289 & 9.243 & 9.150 \\
\hline Omega-9 & & & 2.941 & 3.779 & 6.480 & 6.448 & 6.384 \\
\hline Unsaturated lipid & & & 3.512 & 5.091 & 26.685 & 26.552 & 26.286 \\
\hline Saturated lipid & & & 1.285 & 1.602 & 14.649 & 14.577 & 14.432 \\
\hline MUFA & & & 1.487 & 1.768 & 9.911 & 9.862 & 9.763 \\
\hline PUFA & & & 0.693 & 0.684 & 16.774 & 16.690 & 16.522 \\
\hline
\end{tabular}

$\mathrm{RM} 1=K$. alvarezii, $\mathrm{RM} 2=$ fermented $K$. alvarezii, $\mathrm{C}=$ commercial feed, $\mathrm{EF} 1=$ commercial feed $+0.5 \%$ K. alvarezii, $\mathrm{EF} 2=$ commercial feed $+1.5 \%$ K. alvarezii

Table 4. Physico-chemical water quality parameters during 15 days experimental period

\begin{tabular}{llcc}
\hline Parameter & Unit & Parameter & Tolerance range \\
\hline Salinity & $\mathrm{ppt}$ & $32-41$ & $5-40$ \\
Temperature & ${ }^{\circ} \mathrm{C}$ & $28-30$ & $28-32$ \\
$\mathrm{DO}$ & $\mathrm{mg} / \mathrm{l}$ & $7.3-9.0$ & $>3.0$ \\
$\mathrm{pH}$ & & $7.5-8.5$ & $7.5-9.0$ \\
Ammonium & $\mathrm{ppm}$ & $0.1-0.4$ & $<3.9$ \\
Nitrite & $\mathrm{ppm}$ & $0-0.7$ & $\leq 5$ \\
Nitrate & $\mathrm{ppm}$ & $0-10$ & $\leq 60$ \\
\hline
\end{tabular}

experimental feeds. The amino acid (Table 2) and fatty acid (Table 3) content in RM2 are evenly higher than RM1, except for tryptophane (zero value) in both RMs. This implies that fermentation on K. alvarezii by $10 \%$ S. cerevisiae with six hours-inoculum age on $K$. alvarezii medium allegedly increases protein, amino acid and some fatty acid nutritions compared to $K$. alvarezii raw material itself.

EF1 and EF2 provide essential fatty acid needed by Litopenaeus vannamei (Han et al. 2012), such as linoleic acid ( $\omega 6)$, linolenic acid ( $\omega 3)$, EPA (C 20:5 $\omega 3$ ), DHA (C 22:6 $\omega 3$ ), and poly-unsaturated fatty acid (PUFA), which may enhance health of shrimp, acts as antioxidant and anti-neoplasm in shrimp (Chojnacka et al. 2012; Dayal et al. 2013).

Protein, the important macromolecule to furnish a continuous supply of essential amino acids, influences the growth rate or size of the shrimp. The protein requirement is minimally reported as $25 \%$ of the diet (Davis 2005). In this study, the amino acid profile on C, EF1 and EF2 feed were also analyzed. The amino acid value of EF1 and EF2 feeds both exceeded the $\mathrm{C}$ feed. Alanine, aspartic acid, glutamic acid, proline, serine, tyrosine, lysine and methionine, were contained in EF1 feed and highest in EF2 feed, which at first were not available in C feed (Table 2). The highest amino acids was obtained from EF2 feed, up two to three times higher than $C$ feed. The amino acid profile of EF2 meet the shrimp requirement based on Velasco et al. (2000) and even higher than the reference. The increase in essential amino acid and non-essential amino acid suits the shrimp basic and additional requirement. Those amino acids have important roles in maintaining the growth and survivalof $L$. vannamei PL during nursery. Increment on branched chain amino acid (BCAA), such as isoleusine, valine, and lysine play role as growth promoter on aquaculture organisms (Rahimnejad and Lee 2014). The alanine, glycine and proline are known as osmolytes which participate in intracellular osmoregulation (Lemme 2010), the free amino acids help to maintain SOD capacity and suppress reactive oxygen intermediate (ROIs) inside shrimp regulation system (Li et al. 2015). This suppression will enhance $L$. vannamei PL tolerance against environmental stress, especially during oxidative stress. Three fundamental components of serine protease, namely serine, proline, and histidine were all found rather high in EF2 feed, of $74.3 \mathrm{~g} / \mathrm{kg}$, $55.2 \mathrm{~g} / \mathrm{kg}$ and $12.7 \mathrm{~g} / \mathrm{kg}$, respectively. Serine protease is protein which activate pro-PO to PO enzyme as innate immunity response in penaeids (Song and Li 2014). This enzymatic conversion will trigger the emerging of phenol hydroxylation to yield melanine compound, encasing the pathogenic bacteria or 
foreign substances inside shrimp's body (Guzman et al. 2009). It is one of several mechanisms to enhance innate or non-specific immunity in shrimp and be more resistant against pathogenic bacteria.

\subsection{Shrimp Growth and Survival Performance}

All physical and chemical water quality parameters were maintained at the tolerance level for shrimp during the experimental period (Lazur 2007; Timmons and Ebeling 2007; Boyd and Tucker 2014). Following 15 days of feeding test, it was shown that both EF1 and EF2 feed can significantly increase the specific growth rate, total biomass and survival of the shrimp when compared to the control feed. The highest specific growth rate, total biomass and survival was found in EF2 feed of $10.88 \pm 0.86 \% / d$, $1.60 \pm 0.21 \mathrm{~g}$ and $91.67 \pm 1.53 \%$, respectively. The use of supplemented feed with fermented $K$. alvarezii can significantly increase the shrimp survival of up to $45 \%$ when compared to control feed (Table 5). This could be influenced by the high essential amino acids content (Table 2), including BCAA, osmolyterole free amino acids, and even proteins or enzymes built from amino acid contents (Song and Li 2014) in the EF2 feed, which are suggested by few studies to be able to enhance the growth and survival of shrimp against environmental stress or pathogens (Dayal et al. 2013).

\section{Conclusion}

According to the result in this research to know the effect of fermented Kappaphycus alvarezii feed supplementation on Litopenaeus vannamei postlarvae growth and survival, it has been proved

Table 5. Growth performance and survival result during 15 days experimental period

\begin{tabular}{lllll}
\hline \multirow{2}{*}{ Parameters } & \multirow{2}{*}{ Unit } & \multicolumn{3}{c}{ Treatment } \\
\cline { 3 - 5 } & & \multicolumn{1}{c}{$\mathrm{C}$} & EF1 & EF2 \\
\hline Length & mm & $15.10 \pm 1.3^{\mathrm{a}}$ & $16.30 \pm 0.23^{\mathrm{a}}$ & $16.10 \pm 0.40^{\mathrm{a}}$ \\
SGR & $\% /$ day & $7.72 \pm 0.63^{\mathrm{a}}$ & $10.74 \pm 0.81^{\mathrm{b}}$ & $10.88 \pm 0.86^{\mathrm{b}}$ \\
MBW & gram & $0.021 \pm 0.004^{\mathrm{a}}$ & $0.022 \pm 0.002^{\mathrm{a}}$ & $0.017 \pm 0.003^{\mathrm{a}}$ \\
Biomass & gram & $0.99 \pm 0.092^{\mathrm{a}}$ & $1.56 \pm 0.19^{\mathrm{b}}$ & $1.60 \pm 0.21^{\mathrm{b}}$ \\
Survival & $\%$ & $47.00 \pm 5.00^{\mathrm{a}}$ & $70.00 \pm 3.00^{\mathrm{b}}$ & $91.67 \pm 1.53^{\mathrm{c}}$ \\
\hline Means within the same row followed by the same letters \\
\multicolumn{3}{l}{ are not significantly different $(\mathrm{p}>0.05)$}
\end{tabular}

that the fermented Kappaphycus alvarezii feed supplementation improved white shrimp postlarvae growth performance and survival significantly compared to commercial feed-treatment. This is estimated being caused by the value of essential amino acid content (threonine, leusine, valine, isoleusin, histidine, phenylalanine, arginine, lysine, methionine) and value of non-essential amino acid content (alanine, aspartic acid, glutamic acid, proline, serine and tyrosine), which serve as important protein's building block, growth promoter and survival enhancer, are found higher in fermented $K$. alvarezii supplemented feed rather than commercial feed.

Further examination on the metabolic profile of the shrimp fed with fermented $K$. alvarezii supplemented feed should be performed in order to evaluate the mode of actions of the substrate in the growth and survival improvement in shrimp culture as well as to evaluate the overall quality improvement of the produced shrimp (Suantika et al. 2020; Putri et al. 2021). Additionally, feeding test should also be performed in the grow out phase, in order to gain a more complete knowledge on the effect of the fermented $K$. alvarezii supplemented feed in all the shrimp life cycle.

\section{Acknowledgements}

The authors thank PT. Gapura Akua Kultiva, Bandung, Indonesia for providing K. alvarezii seaweed products used in this study. Authors also thank PT. Suri Tani Pemuka for providing the shrimp postlarvae for the feeding experiment.

\section{References}

Abowei JFN. 2010. Salinity, dissolved oxygen, pH and surface water temperature conditions in Nkoro River, Niger Delta, Nigeria. Advance Journal of Food Science and Technology 2:36-40.

AOAC. 1999. Official Methods of Analysis of AOAC International. 8 ed. Maryland: AOAC International.

APHA. 1999. Standard Methods for the Examination of Water and Wastewater. Washington: American Public Health Association.

Asaduzzaman MD. 2007. Standardization of Yeast Growth Curves from Several Curves with Different Initial Sizes. Sweden: Chalmers University of Technology and Goteborg University. pp. 2-5. 
Boyd CE, Tucker CS. 2014. Handbook for Aquaculture Water Quality. Craftmaster: Printers.

Chojnacka K et al. 2012. Biologically active compounds in seaweed extracts-the prospects for the application. The Open Conference Proceedings Journal 3:20-28.

Davis DA. 2005. Nutrient Requirements of Penaeid Shrimp. St. Louis: Global Aquaculture Advocate.

Dayal JS et al. 2013. Shrimps-a nutritional perspective. Current Science 104:1487-1491.

[FAO] Food and Agriculture Organization. 2020. The State of World Fisheries and Aquaculture 2020. Sustainability in action. Rome. Available at: http://www.fao. org/3/ca9229en/CA9229EN.pdf [Date accessed: 6 September 2021]

Ferreira IMPLVO et al. 2010. Brewer's Saccharomyces yeast biomass: characteristics and potential application. Trends in Food Science and Technology 21:77-84.

Guzman GA et al. 2009. Penaeid shrimp immune system. Thai J Vet Med 39:205-215.

Han L et al. 2012. Research and optimization of technological process based on fermentation for production of seaweed feed. Green and Sustainable Chemistry 2:4754.

Lazur A. 2007. Growout Pond and Water Quality Management. Maryland: JIFSAN Good Aquacultureal Practices Manual Section 6

Lemme A. 2010. Availability and effectiveness of free amino acids in aquaculture. Cruz-Suarez LE, Ricque-Marie D, Tapia-Salazar M, Nieto-López MG, Villarreal-Cavazos DA, Gamboa-Delgado J (Eds.). Avances en Nutrición Acuícola X-Memorias del Décimo Simposio Internacional de Nutrición Acuícola, 8-10 de Noviembre, San Nicolás de los Garza NL, México. México: Universidad Autónoma de Nuevo León, Monterrey. pp. 264-275.

Li E et al. 2015. Physiological change and nutritional requirement of Pacific white shrimp Litopenaeus vannamei at low salinity. Reviews in Aquaculture 7:1-19.

Liu $\mathrm{CH}$ et al. 2004. Vibrio alginolyticus infection in the white shrimp Litopenaeus vannamei confirmed by polymerase chain reaction and $16 S$ rDNA sequencing. Dis Aquat Org 61:169-174.

Marudhupandi T, Inbakandan D. 2015. Polysaccharides in aquatic disease management. Fish Aquac J 6:135. DOI:10.4172/2150-3508.1000135

Nuraida L. 2015. A review: health promoting lactic acid bacteria in traditional Indonesian fermented foods. Food Science and Human Wellness 4:47-55

Putri SLE et al. 2021. Shrimp count size: GC/MS-based metabolomics approach and quantitative descriptive analysis (QDA) reveal the importance of size in white leg shrimp (Litopenaeus vannamei). Metabolomics $17: 19$.

Rahimnejad S, Lee KJ. 2014. Dietary isoleucine influences non-specific immune response in juvenile olive flounder (Paralichthys olivaceus). Turkish Journal of Fisheries and Aquatic Sciences 14:853-862.

Rubel H et al. 2019. Strategic Approach to Sustainable Shrimp Production In Indonesia The Case For Improved Economics And Sustainability. Media Publication by Boston Consulting Group, USA. Available at: https:// media-publications.bcg.com/BCG-A-StrategicApproach-to-Sustainable-Shrimp-Production-inIndonesia-Nov-2019 [Date accessed: 6 September 62021

Situmorang ML et al. 2020. Poly-b-Hydroxybutyrate (PHB) improves nursery-phase pacific white shrimp Litopenaeus vannamei defense against vibriosis. $N$ Am J Aquac 82:108-114.
Situmorang ML et al. 2021. Synbiotic containing Kappaphycus alvarezii, Spirulina sp., and Halomonas alkaliphila improves survival, growth, and vibriosis resistance in whiteleg shrimp (Litopenaeus vannamei) postlarval culture. Aquat Living Resour 34:10. DOI:10.1051/ $\operatorname{alr} / 2021009$

Sivagnanavelmurugan M et al. 2014. Dietary effect of Sargassum wightii fucoidan to enhance growth, prophenoloxidase gene expression of Penaeus monodon and immune resistance to Vibrio parahaemolyticus. Fish Shellfish Immunol 39:439-449.

Song YL, Li CY. 2014. Shrimp immune system-special focus on penaeidin. Journal of Marine Science and Technology 22:1-8.

Suantika G et al. 2003. Technical and economical feasibility of a rotifer recirculation system. Aquaculture 227:173189.

Suantika Get al. 2012. Use of zero water discharge technology through the application of nitrifying bacteria and textile vertical substrate in grow-out phase of Macrobrachium rosenbergii De Man. J Aquacult Res Dev 3:139.

Suantika G et al. 2013. The use of indigenous probiotic Halomonas aquamarina and Shewanella algae for white shrimp (Litopenaeus vannamei Boone) hatchery productivity in zero water discharge system. J Aquac Res Development 4:194

Suantika G et al. 2015. Performance of zero water discharge (ZWD) system with nitrifying bacteria and microalgae Chaetoceros calcitrans components in super intensive white shrimp (Litopenaeus vannamei) culture. Journal of Aquaculture Research and Development 6:359.

Suantika G et al. 2018. Development of a Zero Water (ZWD)_recirculating aquaculture system (RAS) hybrid system for super intensive white shrimp (Litopenaeus vannamei) culture under low salinity conditions and its industrial trial in commercial shrimp urban farming in Gresik, East Java, Indonesia. Aquac Eng $82: 12-24$

Suantika G et al. 2020. Metabolite profiling of whiteleg shrimp Litopenaeus vannamei from super-intensive culture in closed aquaculture systems: a recirculating aquaculture system and a hybrid zero water dischargerecirculating aquaculture system. Metabolomics. 16:49.

Swain MR et al. 2014. Fermented fruits and vegetables of Asia: a potential source of probiotics. Biotechnology Research International 2014:1-19.

Timmons MB, Ebeling JM. 2007. Recirculating Aquaculture. Ithaca: Cayuga Aqua Ventures.

Uawisetwathana U et al. 2021. Supplementation of ex-situ biofloc to improve growth performance and enhance nutritional values of the pacific white shrimp rearing at low salinity conditions. Appl Sci 11:4598.

Uchida M, Miyoshi T. 2013. Algal fermentation-the seed for a new fermentation industry of foods and related products. JARQ 47:53-63.

Velasco $\mathrm{M}$ et al. 2000. Dietary protein requirement for Litopenaeus vannamei. In: Cruz -Suárez LE, RicqueMarie D, Tapia-Salazar M, Olvera-Novoa MA. y Civera-Cerecedo R (Eds.). Simposium Internacional de Nutrición Acuícola. Mérida: Avances en Nutricion Acuicola. pp. 181-192.

Wyban J et al. 1995. Temperature effects on growth, feeding rate and feed conversion of the Pacific white shrimp (Penaeus vannamei). Aquaculture 138:267-279.

Yamada EA, Sgarbieri VC. 2005. Yeast (Saccharomyces cerevisiae) protein concentrate: Preparation, chemical composition and nutritional and functional properties. J Agric Food Chem 53:3931-3936. 